\section{ENTOMOLOGICAL ITEMS.}

M. Dalmas - so Les Mondes informs us - has succeeded in destroying the phylloxera by wrapping thin copper wire round the stems of the vine, and passing the current from a powerful voltaic battery through it. Both the mature insects and their eggs are said to be completely disorganized by the electricity.-Athenaeum, 27 Dec. 1879, p. 853.

The INFLUence of quinine upon silkworms has been satisfactorily proved by C.LeDoux. Broods of caterpillars suffering from flacquerie were speedily restored by sprinkling their food with quinine sulphate. The same treatment proved successful in cases of "pebrine" with open wounds.-Mo.journ.sci., Nov. 1879, s. 3, v. 1, p. 765.

A Revision of the Lampyridae will shortly be published by Mr. Henry S. Gorham of Shipley, Horsham, England. Mr. Gorham would be glad to see specimens of this group from America, and especially from Central America below the United States to the Isthmus of Darien. He also desires to obtain specimens of the genera Pleotomus LeC., Phausis LeC., Microphotus LeC., Phengodes Hof., and Pierotus LeC.

Abrasion orl is, according to the "Est. Land wirth. Wochenblatt," obtained in China from the seeds of Elaeococca cordata, and is said to be an excellent protective against noxious insects. The tree, which belongs to the family of the Euphorbiaceae, prospers in the south of France, where its culture is recommended, in the hope of the oil proving a specific for the Phylloxera and the Oidium. - Mo. journ. sci., Nov. 1879, s. 3, v. 1, p. 756.

Cases of poisoning by caterpillars have been observed both in cows and ducks. The former experienced gastric symptoms, diarrhoea, loss of appetite, \&c., but were all restored by means of mucilaginous drinks and a diet of boiled potatoes and bran. Ninety ducks were turned into a cabbage-field infested with the caterpillars of the common white (Pieris brassicae). In one afternoon the field was almost clear, but two ducks died after an hour. The next morning twenty were found dead, and altogether fifty-three perished. The flesh of the dead, on examination, was found to resemble that of cattle which die of gangrene, indicating true poisoning. - Mo. journ. sci., Nov. 1879, s. 3, v. 1, p. 765.

\title{
SOCIETY MEETINGS.
}

The Regular meetings of the Cambridge Entomological Club will be held at 19 Follen St., at $7.45 \mathrm{p} . \mathrm{m}$. , on the days following :-

$\begin{array}{ll}9 \text { Jan. } 1880 . & 9 \text { April } 1880 . \\ 13 \text { Feb. }, & \text { 14. May " } \\ 12 \text { Mar. " } & \text { 11 June " }\end{array}$

B: Pickman Mann, Secretary.

The Regular meetings of the Entomological Section of the Boston Society of Natural History will be held at N. W. corner of Berkeley and Boylston Sts., Boston, Mass., at 7.45 p.m., on the days following :-

28 Jan. 1880.

25 Feb.

24 Mar. ,

\section{B: Pickman Mann, Secretary.}

The annual meetings of the Entomological Section of the American Association for the Advancement of Science will begin at $2 \mathrm{p}$. m., on Tuesday, 24 Aug. 1880, at a place yet to be determined, in Boston, Mass. Members who intend to present communications that may provoke discussion are requested to allow the Secretary to announce their subjects, in order that other members may come ready to enter into a thorough discussion.

\section{B: Pickman Mann, Secretary,} Cambridge, Mass.

The REgular meetings of the Entomological Section of the Academy of Natural Sciences, of Philadelphia, Pa., will be held at S. W. corner of 19th and Race Sts., on the days following:-

$\begin{array}{lc}9 \text { Jan. } 1880 . & 9 \text { Apr. } 1880 . \\ 13 \text { Feb. }, & 14 \text { May " } \\ 12 \text { Mar. " } & 11 \text { June " } \\ & \text { JaMes H. Ridings, } \\ & \text { Recorder. }\end{array}$

The semi-annual meetings of the American Entomological Society will be held at S. W. corner of 19th and Race Sts., Philadelphia, Pa., on the days following:-

8 Dec. 1879.

14 June 1880.

JAMes H. Ridings, Recording Secretary. 

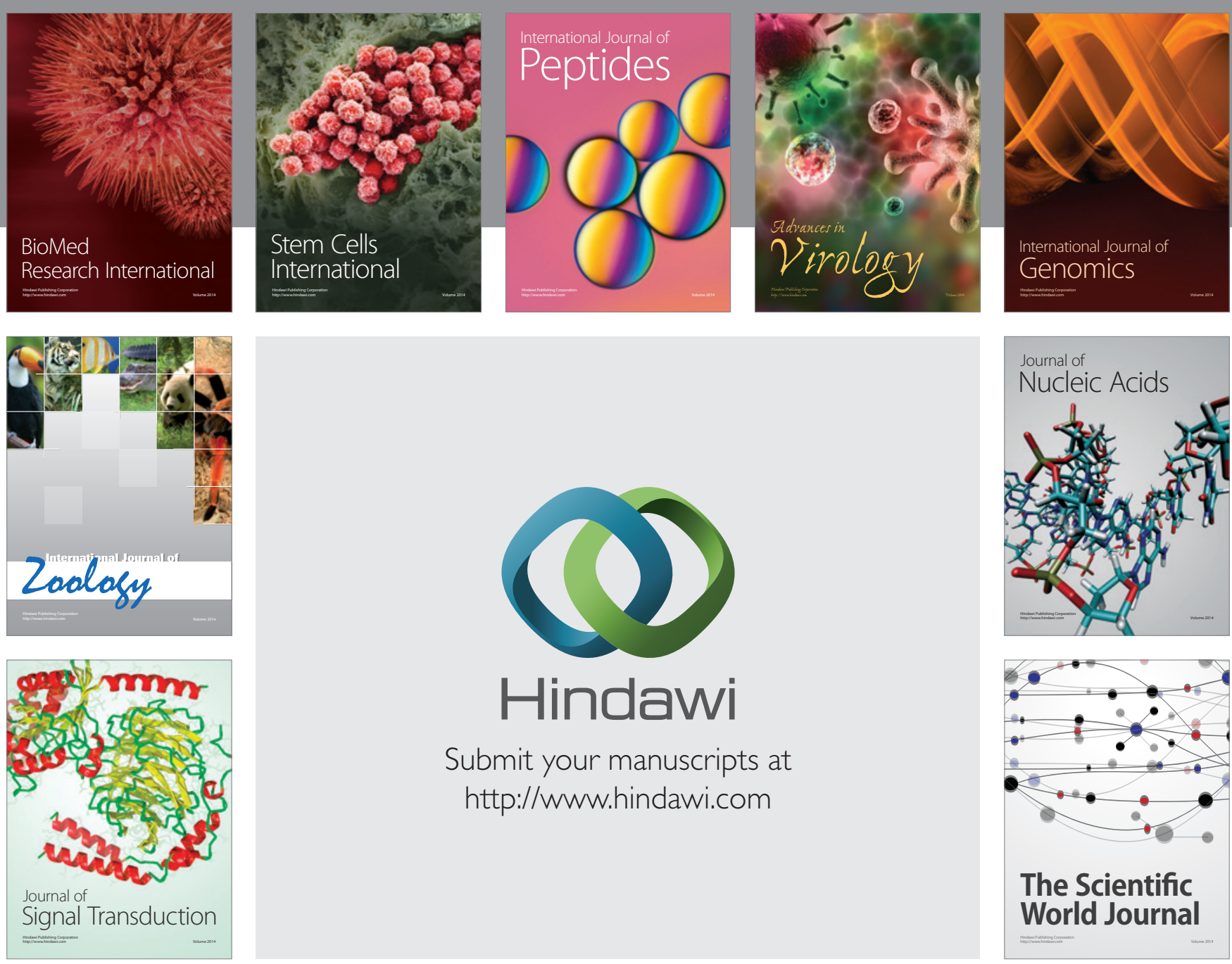

Submit your manuscripts at

http://www.hindawi.com
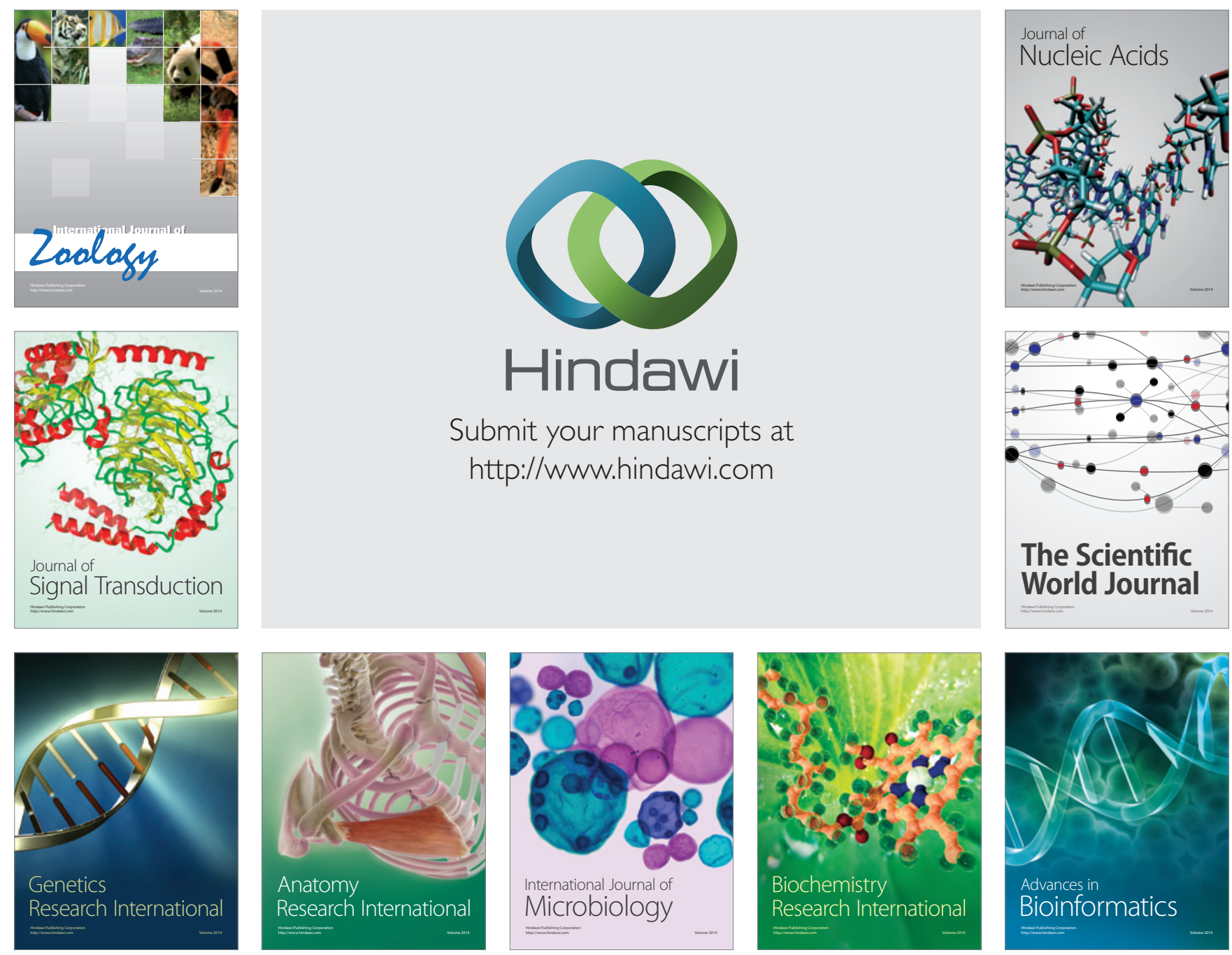

The Scientific World Journal
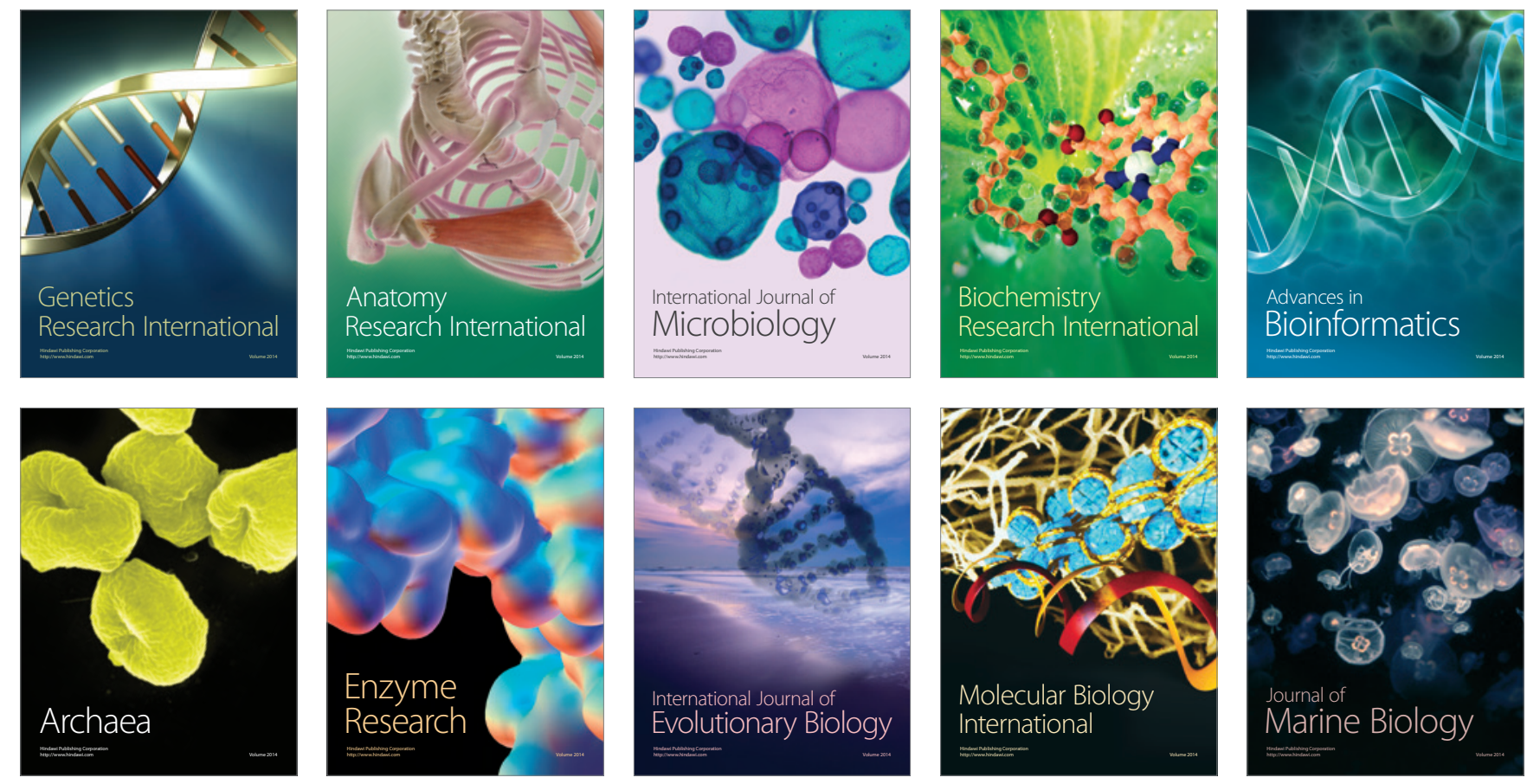